\title{
A comparative study on Musa paradisiaca L. and co-processed super disintegrants in the formulation and evaluation of flubiprofen orodispersible tablets
}

\section{Rajesh Babu* and Suresh Kumar Dev}

Department of Pharmaceutical Sciences, Faculty of Pharmacy, Pacific Academy of Higher Education and Research University, Udaipur313024, Rajasthan, India

\section{Article Info}

\section{Article history}

Received 1 October 2021

Revised 17 November 2021

Accepted 19 November 2021

Published Online 30 December 2021

\section{Keywords}

Flubiprofen

Musa paradisiaca $\mathrm{L}$.

Co-processed

Superdisintegrants

Orodispersible tablets

\begin{abstract}
For decades, oral drug delivery system has been recognized as the most extensively used route of administration among all the ways that have been investigated for systemic drug delivery via diverse pharmaceutical products in various dosage forms. Because of the convenience of self-administration, the tablet is the most widely used of all current dosage forms. Dysphagia is a common problem that affects people of all ages when it comes to solid dosage forms. For treating dysphagia and improving patient compliance, orodispersible tablets have emerged as a feasible alternative to standard oral drug formulations. Flubiprofen (non-steroidal anti-inflammatory agent) orodispersible tablets were formulated with co-processed superdisintegrants in various ratios (crospovidone and SSG 1:1, 1:2, 1:3, 3:1, 2:1), a physical mixture of crospovidone and SSG and a control formulation (without superdisintegrnats), and Musa paradisiacal L. (unripe banana) powder in various concentrations ( 2 per cent, 4 per cent, 6 per cent, and 8 per cent) by using the direct compression approach with microcrystalline cellulose, mannitol as diluents, aspartame as sweetener, aerosil as glidant, magnesium stearate as lubricant. Flubiprofen orodispersible tablets prepared with coprocessed superdisintegrants (crospovidone and SSG 3:1 ratio) demonstrated the shortest wetting time of $12 \mathrm{sec}$, a water absorption ratio of more than 92 per cent, the shortest disintegration time of $15 \mathrm{sec}$, the shortest dispersion time of $11 \mathrm{sec}$ and better drug release characteristics of more than 95 per cent in 20 min when compared to natural superdisintegrant M. paradisiaca powder. This is a novel work that should be recommended for increasing the rate of disintegration, dissolution, and bioavailability of flubiprofen orodispersible tablets by using co-processed superdisintegrants when compared to natural superdisintegrant M. paradisiaca. This method is simple and cost-effective.
\end{abstract}

\section{Introduction}

Among all the known routes for systemic distribution of diverse pharmacological drugs, the oral route has been the most commonly employed for decades. Patient compliance with a traditional belief that drugs administered through the oral route get absorbed well like the daily ingested food stuffs due to ease of administration, cost effectiveness, easy to swallow, dose precision with least content variability, self administration, good microbial and chemical stability, ease of manufacturing and packing, and patient compliance with a traditional belief that drugs administered through the oral route get absorbed well like the daily ingested food stuffs (Vidyadhara et al., 2017). The development and optimization of ODDS, regardless of its physical form, within the physiology of GI limits, necessitates a deeper understanding of the foundations of formulation design, its pharmacokinetics and dynamics, as well as knowledge of GI physiology. The complexity of constructing and optimizing a sophisticated formulation is higher, including multiple disciplines (Saleh et al., 2017). Orodispersible tablets are a sort of mouth dissolving tablet that is defined as "a solid dosage form containing a medicine or active component that dissolves quickly when placed

Corresponding author: Mr. V. Rajesh Babu

Research Scholar, Department of Pharmaceutical Sciences, Faculty of Pharmacy, Pacific Academy of Higher Education and Research University, Udaipur-313024, Rajasthan, India

E-mail: rajeshbabuvemula @gmail.com

Tel.: +91-9989818594

Copyright (C) 2021 Ukaaz Publications. All rights reserved.

Email: ukaaz@yahoo.com; Website: www.ukaazpublications.com on the tongue, usually within seconds." ODTs might take anything from a few seconds to a minute to dissolve (Vivek et al., 2017). The scientific basis for successful ODDS development necessitates a basic understanding of three aspects: drug physicochemical, pharmacokinetic, and dynamic properties, GIT physiologic and anatomic properties and dosage forms drug administration mechanism and physicochemical properties (Prasad et al., 2016).

\subsection{M. paradisiaca (Banana)}

Banana is the popular name for M. paradisiaca, a herbaceous plant with a sturdy tree-like pseudostem and a crown of huge elongated oval deep-green leaves (up to $365 \mathrm{~cm}$ in length and $61 \mathrm{~cm}$ in breadth). Each plant has a single $15-20 \mathrm{~cm}$ long inflorescence that is concave, dark crimson in colour, and slightly mushy. Fruits are rectangular, meaty, and range in length from $5-7 \mathrm{~cm}$ in the wild to longer in cultivated forms. Musa sapientum is a perennial herb with a tuberous rhizome that grows 5 to 9 metres tall. With a reddish-brown bract, the inflorescence is large. The pulp of the fruit is soft, luscious, and full of seeds. Around $600 \mathrm{BC}$, the banana plant migrated from its natural south-western Pacific home to India, and then to the rest of the tropical world. It is the most prevalent tropical fruit and possibly the world's oldest farmed crop. Bananas are grown in around 300 different types, the most majority of which are distributed throughout tropical and subtropical regions. Diarrhoea (unripe), dysentery, intestinal lesions in ulcerative colitis, diabetes (unripe), sprue, uraemia, 
nephritis, gout, hypertension, and heart disease have all traditionally been treated using $M$. paradisiaca and $M$. sapientum fruit.

\subsubsection{Pharmacological actions include}

Bananas are said to be one of the best suppliers of potassium, which is necessary for good blood pressure and heart function. A medium banana contains 350 milligrammes of potassium. Potassium-rich diets have been shown to be useful in lowering blood pressure in a number of trials. The FDA has given its approval to claims made by the banana industry that it can lower the risk of hypertension and stroke.

\subsubsection{Properties of unripe banana}

Bananas are high in carbohydrates, with starch accounting for roughly 70 to 80 per cent of the dry weight of an unripe banana. Its use as a tablet disintegrant is due to its high starch content. During ripening, the average starch content drops from more than $10 \%$ of the fresh weight of the fruit in the pre-climacteric (prior to starch breakdown) period to less than $1 \%$ at the end of the climacteric period, when sugars, primarily sucrose, accumulate to more than $10 \%$ of the fresh weight of the fruit (Figure 1).

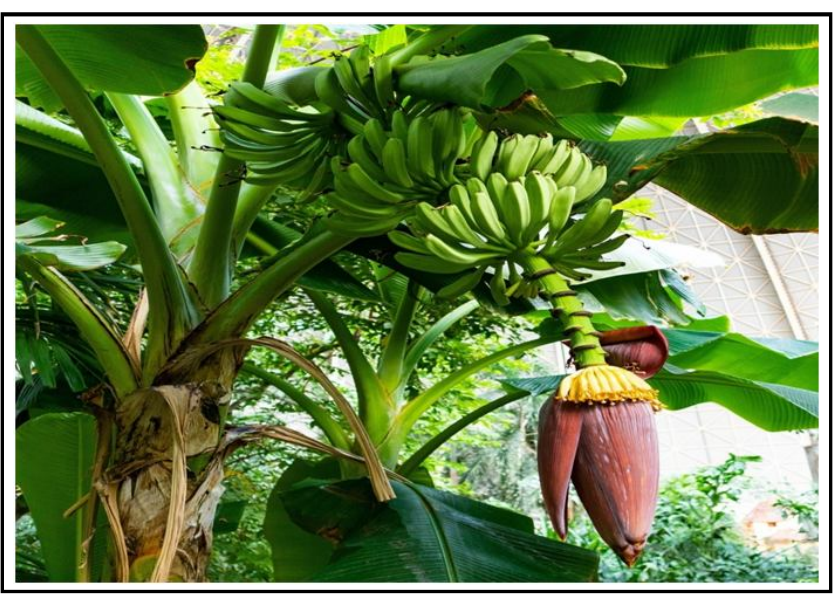

Figure 1: Banana fruit.

\section{Materials and Methods}

\subsection{Materials}

Flubiprofen was procured from Aurobindo Pharmaceuticals, Hyderabad; $M$. paradisiaca (unripe bananas) were collected locally and from herbal drug store and were authenticated before use, all other ingredients obtained from SD Fine Chemicals Pvt. Ltd., Hyderabad.

\subsection{Preparation and extraction of M. paradisiaca powder}

Unripe bananas from the Musaceae family were peeled and the fruit's edible section was sliced. The sliced pulp was rinsed with distilled water and a preservative of 0.2 per cent w/w methyl paraben was applied. The pulp was crushed in a home blender and dried for $24 \mathrm{~h}$ in a convection oven at $45^{\circ} \mathrm{C}$. The dry pulp was ground in a mortar, sieved using sieve No. $80(177 \mathrm{~m})$, and kept in an airtight container with a desiccant (silica gel packets).

A magnetic stirrer was used to agitate dehydrated banana powder ( $20 \mathrm{~g}$ ) containing $100 \mathrm{ml}$ of distilled water for $12 \mathrm{~h}$ at room temperature. Mesh 200 was used to filter the mixture. The filtrate was centrifuged at $1000 \mathrm{x} \mathrm{g}$ for $30 \mathrm{~min}$ at room temperature after the residue was rinsed with distilled water. The supernatant was removed and the wet mass was dried for $12 \mathrm{~h}$ at $40^{\circ} \mathrm{C}$ in a convection oven. The dry substance was pulverised in a mortar, sieved using sieve No. 80 and kept with a desiccant in an airtight container.

\subsection{Characterization of the M. paradisiaca powder}

The macroscopic features and overall aesthetics of natural superdisintegrants were determined through sensory evaluation. The taste, color, aroma, and texture were all evaluated. Phytochemical study was performed to get a qualitative understanding of the chemical makeup of M. paradisiaca natural superdisintegrant. Phytochemicals can have therapeutically significant effects that are either useful or harmful. Carbohydrates, saponins, phenols, proteins, gums, mucilage, tannins, lipids, flavonoids, and steroids were measured in M. paradisiaca powder.

\subsection{Phytochemical analysis of $M$. paradisiaca}

This Assessment was conducted to gain an insight of the chemical composition of the natural superdisintegrant from a qualitative perspective. Phytochemicals can have potentially beneficial or detrimental therapeutically significant effects. Samples of $M$. paradisiaca powder were evaluated for the presence of carbohydrates, saponins, phenols, proteins, gums, mucilage, tannins, lipids, flavonoids and steroids.

\subsubsection{Iodine test}

$1 \mathrm{~g}$ of powder was dissolved in $15 \mathrm{ml}$ of distilled water. The solution was boiled until mucilage was obtained. Few drops of $2 \mathrm{~N}$ iodine solution were added to $2 \mathrm{ml}$ of the mucilage. A dark blue colouration was an indication of the presence of starch.

\subsubsection{Foam test}

$1 \mathrm{~g}$ of powder was dissolved in $10 \mathrm{ml}$ of distilled water in a test tube. The test tube was sealed and agitated vigorously. The appearance of a permanent froth was a positive test for saponins.

\subsubsection{Phenols}

An aqueous extract of the polymer was treated with $\mathrm{FeCl}_{3}$. A dark colouration was an indication of the presence of phenols.

\subsubsection{Biuret test}

A small amount of powder was added to $4 \% \mathrm{NaOH}$ and few drops of $1 \% \mathrm{CuSo}_{4}$ were added. The appearance of a violet or pink colour was an indication of the presence of proteins.

\subsubsection{Tannins}

An aqueous extract of the polymer was treated with $\mathrm{FeCl}_{3}$. A dark colouration was an indication of the presence of tannins.

\subsubsection{Lipids}

$10 \mathrm{ml}$ of $96 \%$ ethanol were added to $1 \mathrm{~g}$ of powder in a test tube and agitated. The solution was diluted with distilled water and the appearance of a cloudy emulsion was an indication of the presence of lipids.

\subsubsection{Flavonoids}

Four pieces of magnesium ribbons were added to the ethanolic extract of the powder sample. Few drops of concentrated hydrochloric acid were added to the extract and agitated. The appearance of a reddish colouration was an indication of the presence of flavonoids. 


\subsubsection{Liberman-burchard test}

$1 \mathrm{~g}$ of powder sample was dissolved in dry chloroform and several drops of acetic anhydride were added followed by 2 drops of concentrated sulphuric acid. A pink, purple or dark colouration was an indication of the presence of steroids such as cholesterol.

\subsubsection{Benedict's test}

$1 \mathrm{~g}$ of powder was dissolved in $10 \mathrm{ml}$ distilled water and placed in a test tube. Few drops of Benedict's reagent were added, and the test tube was placed in a hot water bath for $10 \mathrm{~min}$. A reddish, yellowish or greenish colouration indicated the presence of monosaccharides (reducing sugars).

2.5 Compatibility studies using IR spectroscopy for drugs and excipients

IR tests were conducted on the drug material alone and the drug substance mixed with excipients. Weighed about one milligramme of flubiprofen medication ingredient and uniformly combined it with $99 \mathrm{mg}$ of potassium bromide that had been dried in a hot air oven at $60^{\circ} \mathrm{C}$ for two hours. The combination was compacted under high pressure to form a transparent pellet, which was then scanned for percentage transmittance using an IR spectrophotometer. Flubiprofen was scanned after the same technique was conducted with the excipient mixture.

\subsection{Preparation of flubiprofen orodispersible tablets}

Direct compression method was used to prepare flubiprofen orodispersible tablets. All the materials, flubiprofen, microcrystalline cellulose (MCC), mannitol, co-processed superdisintegrants, unripe banana powder, aspartame were passed through the sieve \# 60 separately to attain uniformity and proper mixing of all the ingredients and collected separately in polyethylene bag. Aerosil, mag. stearate were sieved \# 40, mixed and blended with above powder blend in tumbling mixer. The entire powder blend was directly compressible into tablets with $10 \mathrm{~mm}$ round shaped, flat punches using eight station rotary tablet compression machine. $\mathrm{F}_{0}$ formulation containing without superdisintegrants, $\mathrm{F}_{1}-\mathrm{F}_{5}$ formulations containing different ratios of co-processed superdisintegants (crospovidone and SSG, 1:1, $1: 2,1: 3,3: 1,2: 1$ ratio), $\mathrm{F}_{6}$ formulation prepared with the physical mixture of crospovidone and SSG, $\mathrm{F}_{7}-\mathrm{F}_{10}$ were formulated with unripe banana powder as superdisintegrants with various concentrations $(2 \%, 4 \%, 6 \%$ and $8 \%)$, microcrystalline cellulose, mannitol used as diluents, aspartame used as sweetener, aerosil used as glidant, magnesium stearate used as lubricant (Table 1).

\subsection{Pre and post compression studies}

The main objective of the preformulations studies is to generate use full information to the formulator to design an optimum drug delivery system. Bulk density, tapped density, carr's index, hausner's ratio and angle of repose (q) of the powders was performed.

\subsubsection{Thickness}

Digital vernier callipers were used to determine the thickness of the tablets. The thickness of the material to be compressed under compression force is mostly determined by the die filling and physical qualities of the material to be compressed. Three pills from each formulation were chosen at random and mean and standard deviation values were determined. It is measured in millimetres.

\subsubsection{Hardness}

The tablet hardness was determined using a monsanto hardness tester. The tablet was held between two jaws, one fixed and the other movable. The scale was set to zero load and then steadily increased until the tablet broke. The load value at that moment is used to determine the tablet's hardness. Three tablets were chosen at random from each formulation, and the mean and standard deviation were computed. It is measured in kilogrammes per square metre.

\subsubsection{Friability}

Tablets friability can be determined by Roche friabilator. This consists of a plastic chamber that revolves at $25 \mathrm{rpm}$; tablets were dropped from six inches height through a head space of the plastic chamber. Then friabilator was operated for 100 revolutions and then tablets are reweighed. The tablets loose less than $1.0 \%$ of its original weight are considered as acceptable.

\subsubsection{Weight variation test}

Twenty tablets were taken randomly, weighed individually and calculated average weight of twenty tablets and compared the individual tablet weight with average tablet weight. If, no more than two of the individual masses vary from the average weight by more than the percentage deviation, and none deviates by more than twice that percentage, the pill passes the uniformity of weight limitations test.

\subsubsection{Wetting time}

The method was used to determine the amount of time, it took for a tablet to wet. A tablet was placed on a piece of tissue paper folded twice and placed in a tiny petridish (i.d. $=6.5 \mathrm{~cm}$ ) containing $10 \mathrm{ml}$ water, and the time for complete wetting was measured.

\subsubsection{In vitro dispersion time}

One tablet was placed in a beaker containing $10 \mathrm{ml}$ of phosphate buffer, and the time it took for complete dispersion was calculated at $37 \pm 2^{\circ} \mathrm{C}$.

\subsubsection{Water absorption ratio}

In a small petridish containing $6 \mathrm{ml}$ of water, a piece of tissue paper folded twice was inserted. A tablet was placed on the paper, and the time it took to completely wet, it was recorded. After that, the wetted pill was weighed.

\subsubsection{In vitro disintegration time}

Disintegration is the process of breaking down a tablet into smaller particles. Disintegration apparatus was used to determine the in vitro disintegration time of a tablet according to I.P requirements.

\subsubsection{Assay}

Assay is very essential parameter to determine the content of drug substance in the drug product. Assay is mainly performed for optimized test product by using UV method. In a mortar, three tablets were weighed and crushed then weighed powder contain equivalent to $100 \mathrm{mg}$ of drug transferred in $100 \mathrm{ml}$ of dissolution media. The solution in the volumetric flask was then filtered; suitable dilutions were be carried out and final solution were analysed at 247 $\mathrm{nm}$ using UV visible spectrophotometer. 


\subsubsection{In vitro drug release studies}

In vitro dissolution of flubiprofen orodispersible tablets was performed in USP XXIII type-II dissolution apparatus at $50 \mathrm{rpm}$. $900 \mathrm{ml}$ of $\mathrm{pH} 7.2$ phosphate buffer was used as dissolution medium. Throughout the experiment, the temperature of the dissolution medium was kept constant at $37 \pm 0.5^{\circ} \mathrm{C}$. In each test, one tablet was used. Samples of dissolution medium $(5 \mathrm{ml})$ were withdrawn by means of syringe fitted with pre-filter at known intervals of time and analyzed for drug release by measuring the absorbance at $247 \mathrm{~nm}$. At each time interval, the volume withdrawn was replaced with a fresh quantity of dissolution medium. The cumulative percentage of drug released was computed and plotted against time.

\subsubsection{Kinetic study}

The in vitro release characteristics observed for all formulations were represented in the following modes of data treatment:

i. Zero - order kinetic model - cumulative \% drug released versus time.

ii. First - order kinetic model - log cumulative per cent drug remaining versus time.

iii. Higuchi model - cumulative per cent drug released versus square root of time.

iv. Korsmeyer equation/peppas model-log cumulative per cent drug released versus log time.

Table 1: Composition of flubiprofen orodispersible tablets

\begin{tabular}{|c|l|c|c|c|c|c|c|c|c|c|c|c|}
\hline S.No & Ingredients (mg/tab) & $\mathbf{F}_{\mathbf{0}}$ & $\mathbf{F}_{\mathbf{1}}$ & $\mathbf{F}_{\mathbf{2}}$ & $\mathbf{F}_{\mathbf{3}}$ & $\mathbf{F}_{\mathbf{4}}$ & $\mathbf{F}_{\mathbf{5}}$ & $\mathbf{F}_{\mathbf{6}}$ & $\mathbf{F}_{\mathbf{7}}$ & $\mathbf{F}_{\mathbf{8}}$ & $\mathbf{F}_{\mathbf{9}}$ & $\mathbf{F}_{\mathbf{1 0}}$ \\
\hline 01 & Flubiprofen & 50 & 50 & 50 & 50 & 50 & 50 & 50 & 50 & 50 & 50 & 50 \\
02 & Co-processed superdisintegrants & - & 16 & 16 & 16 & 16 & 16 & 16 & - & - & - & - \\
03 & Unripe banana powder & - & - & - & - & - & - & - & 04 & 08 & 12 & 16 \\
04 & MCC & 100 & 100 & 100 & 100 & 100 & 100 & 100 & 100 & 100 & 100 & 100 \\
05 & Mannitol & 44 & 28 & 28 & 28 & 28 & 28 & 28 & 40 & 36 & 32 & 28 \\
06 & Aspartame & 2 & 2 & 2 & 2 & 2 & 2 & 2 & 2 & 2 & 2 \\
07 & Aerosil & 2 & 2 & 2 & 2 & 2 & 2 & 2 & 2 & 2 & 2 \\
08 & Mag.stearate & 2 & 2 & 2 & 2 & 2 & 2 & 2 & 2 & 2 & 2 \\
& Total tablet weight & 200 & 200 & 200 & 200 & 200 & 200 & 200 & 200 & 200 & 200 & 200 \\
\hline
\end{tabular}

\section{Results}

The dried pulp of unripe bananas of the genus, Musa yielded a pale yellow powder. This powder was very smooth to the touch and smelled faintly sweet and floury. By centrifuging a suspension of unripe banana powder, a white smooth powder with no distinguishing odor was obtained (Table 2).

Table 2: Organoleptic and physical properties of unripe banana powder

\begin{tabular}{|l|l|}
\hline Parameter & Unripe banana powder \\
\hline Appearance/color & Pale yellow \\
Taste & Faint sweet \\
Odor & Floury \\
Solubility & Slightly swells in water \\
LOD & $10 \%$ \\
Swelling index & $10 \%$ \\
Viscosity & $8.42 \mathrm{cps}$ \\
Total ash & $2.8 \%$ \\
Water soluble ash & $0.53 \%$ \\
Acid soluble ash & 0.59 \\
pH & 5.2 \\
Texture & Soft and smooth \\
\hline
\end{tabular}

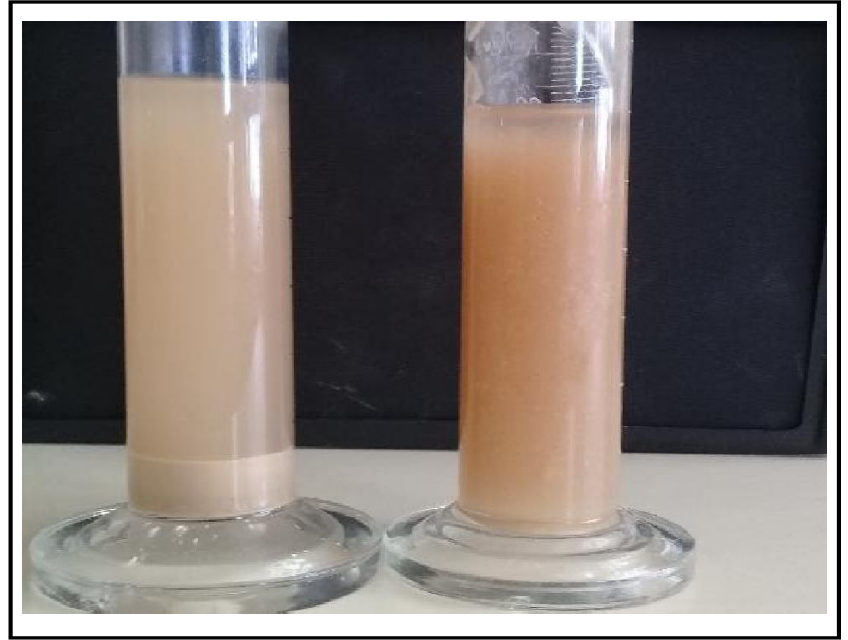

Figure 2: Swelling index of unripe banana powder.

Identification and characterisation of the $M$. paradisiaca (unripe banana powder) evaluated for the presence of carbohydrates, saponins, phenols, proteins, gums, mucilage, tannins, lipids, flavonoids and steroids. Unripe banana powder has a high content of carbohydrates with starch being the main constituent accounting for about 60 to $80 \%$ on a dry weight basis, arabinoxylan is a gel forming polysaccharide which comprises of about $23 \%$ arabinose and $75 \%$ xylose on molar basis, starch, saponins, phenols, proteins, tannins, lipids, flavonoids and reducing sugars were identified in UBP. The phytochemical profile of UBP obtained in this study is in concordance with literature (Table 3). 
Table 3: Phytochemical profile of the UBP

\begin{tabular}{|l|l|}
\hline Phytochemical property & Unripe banana powder \\
\hline Phenols & Observed \\
Proteins & Observed \\
Tannins & Observed \\
Steroids & Not observed \\
Lipids & Observed \\
Starch & Observed \\
Flavonoids & Observed \\
Monosaccharides & Observed \\
Saponins & Observed \\
\hline
\end{tabular}

No physical change was observed between room temperature and $99^{\circ} \mathrm{C}$ under hot stage microscopy (HSM). At $100^{\circ} \mathrm{C}$, temperature at which the boiling point of water occurs, solvent extrusion and bubbling was observed. This indicated the presence of moisture in the sample. The physical aspect of the powder remained unchanged between $100^{\circ} \mathrm{C}$ and $190^{\circ} \mathrm{C}$. At $200^{\circ} \mathrm{C}$, a colour change from pale yellow to light brown was observed. (Figure 3 ).

Physical observation and FTIR measurements to determine drug and excipient compatibility. Physical observation, chemical analysis, and FTIR tests were used to find the drug flubiprofen. The findings revealed that after one month of accelerated conditions $\left(40^{\circ} \mathrm{C} / 75 \%\right.$ $\mathrm{RH}$ and $\left.50^{\circ} \mathrm{C} / 75 \% \mathrm{RH}\right)$, no colour change in the drug component and excipient mixture was found. An FTIR studies found that the medication and excipient mixture are compatible, because the absorption peaks were discovered to be comparable. This means that under physical observation and FTIR measurements, both drugs were compatible with specific excipients (Figure 4).

Precompression evaluation parameters such as bulk density, tapped density, angle of repose, hausners ration, and compressibility index showed that all of the prepared formulations had good flow properties, compatibility, and compressibility index that were within the range (Table 4).

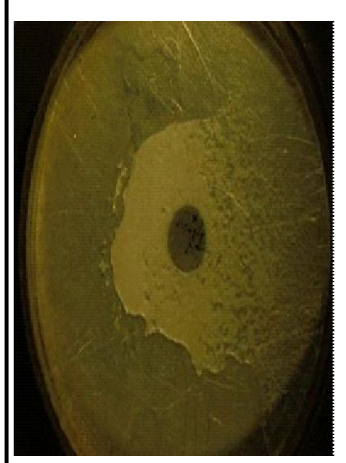

$21^{\circ} \mathrm{C}$

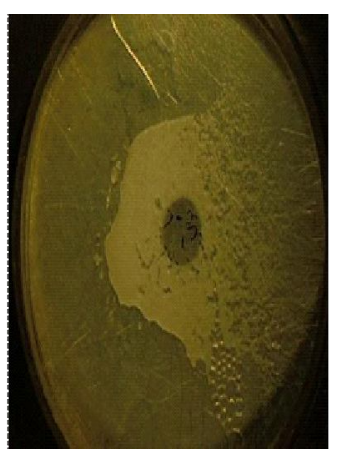

$100^{\circ} \mathrm{C}$

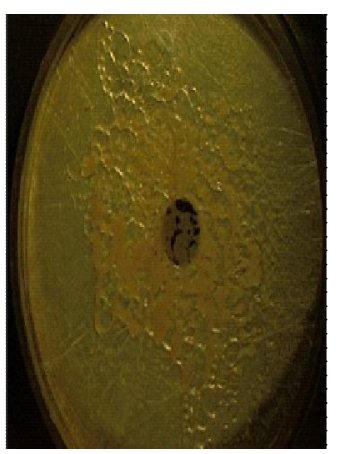

$200^{\circ} \mathrm{C}$

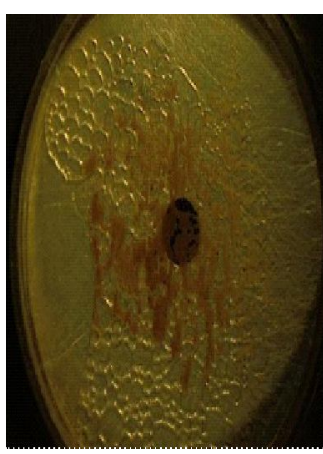

$250^{\circ} \mathrm{C}$

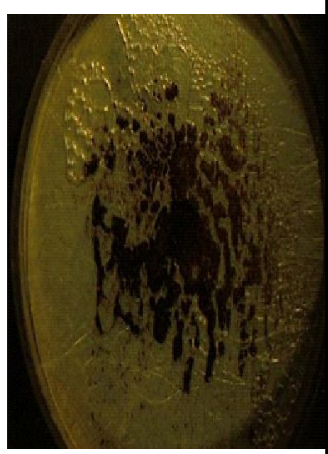

$300^{\circ} \mathrm{C}$

Figure 3: HSM images of unripe banana powder.

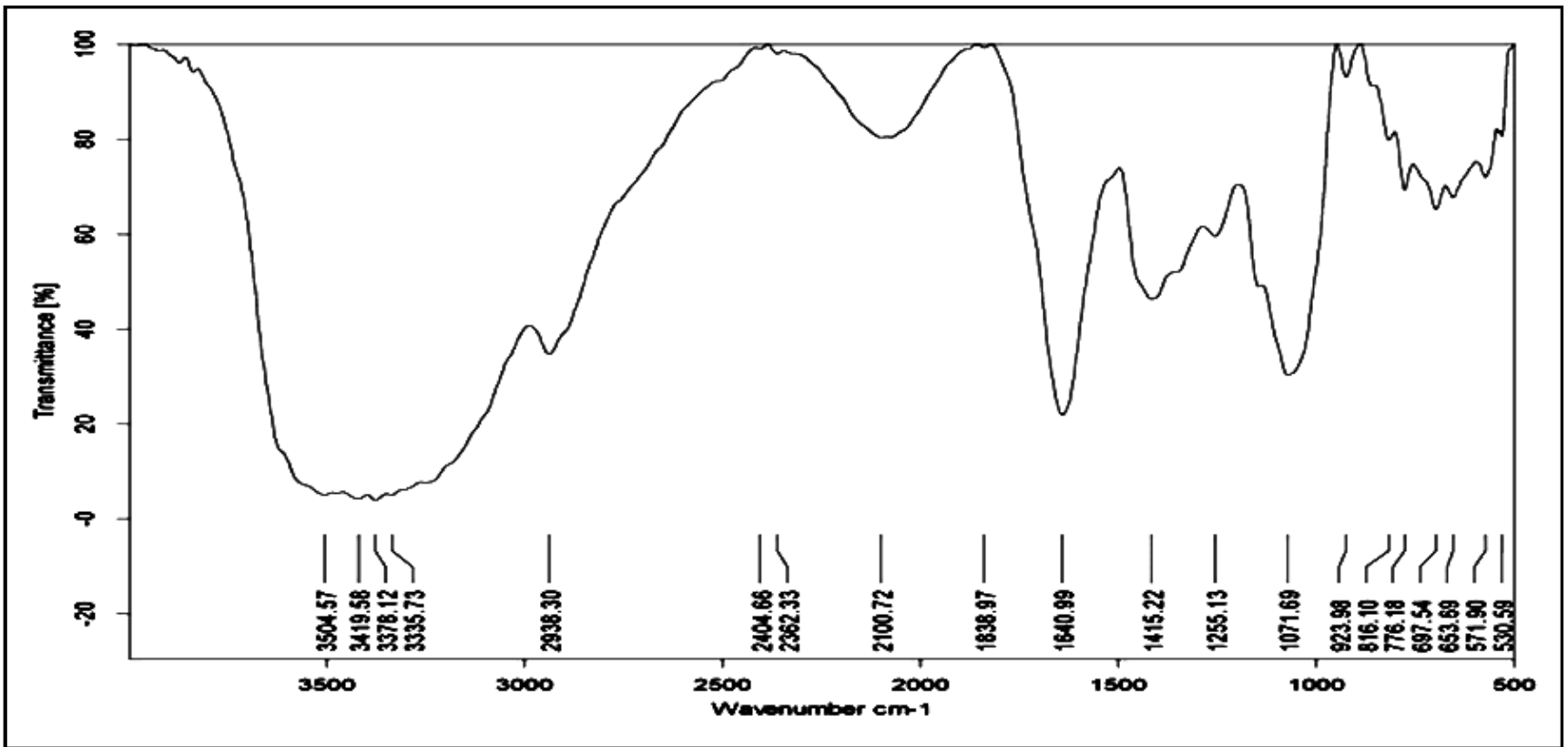

Figure 4: IR spectrum of unripe banana powder. 
Table 4: Micromeritic properties of flubiprofen powder blend

\begin{tabular}{|c|c|c|c|c|c|}
\hline Formulation code & Bulk density (g/cc) & Tapped density (g/cc) & $\begin{array}{c}\text { Angle of repose } \\
\text { (degree) }\end{array}$ & Carr's index (\%) & Hausner's ratio \\
\hline $\mathrm{F}_{0}$ & 0.66 & 0.78 & 32.48 & 15.38 & 1.18 \\
\hline $\mathrm{F}_{1}$ & 0.70 & 0.81 & 26.13 & 13.58 & 1.15 \\
\hline $\mathrm{F}_{2}$ & 0.69 & 0.80 & 25.12 & 13.75 & 1.15 \\
\hline $\mathrm{F}_{3}$ & 0.71 & 0.84 & 28.56 & 15.47 & 1.18 \\
\hline $\mathrm{F}_{4}$ & 0.69 & 0.76 & 32.96 & 9.21 & 1.10 \\
\hline $\mathrm{F}_{5}$ & 0.68 & 0.74 & 25.68 & 8.10 & 1.08 \\
\hline $\mathrm{F}_{6}$ & 0.71 & 0.79 & 28.08 & 10.12 & 1.11 \\
\hline $\mathrm{F}_{7}$ & 0.73 & 0.78 & 26.10 & 6.41 & 1.06 \\
\hline $\mathrm{F}_{8}$ & 0.71 & 0.77 & 28.20 & 7.79 & 1.08 \\
\hline $\mathrm{F}_{9}$ & 0.72 & 0.76 & 26.72 & 5.26 & 1.05 \\
\hline $\mathrm{F}_{10}$ & 0.72 & 0.78 & 28.56 & 7.69 & 1.08 \\
\hline
\end{tabular}

Table 5: Post compression parameters of formulations

\begin{tabular}{|c|c|c|c|c|}
\hline Formulation code & Wetting time $(\mathbf{s e c})$ & Water absorption ratio $(\%)$ & Disintegration time (sec) & In vitro dispersion time (sec) \\
\hline$F_{0}$ & $202.21 \pm 1.24$ & $22.16 \pm 0.49$ & $163.2 \pm 1.62$ \\
$F_{1}$ & $28.12 \pm 1.31$ & $62.11 \pm 1.61$ & $30.01 \pm 1.18$ \\
$F_{2}$ & $21.68 \pm 1.02$ & $79.06 \pm 1.28$ & $26.33 \pm 0.31$ \\
$F_{3}$ & $19.35 \pm 1.83$ & $86.36 \pm 1.03$ & $22.57 \pm 0.42$ \\
$F_{4}$ & $12.47 \pm 1.29$ & $99.31 \pm 1.15$ & $15.21 \pm 2.50$ \\
$F_{5}$ & $16.22 \pm 1.12$ & $92.53 \pm 1.4$ & $19.11 \pm 2.50$ \\
$F_{6}$ & $32.24 \pm 0.56$ & $77.35 \pm 1.52$ & $29.01 \pm 0.52$ \\
$F_{7}$ & $30.33 \pm 1.59$ & $68.36 \pm 1.81$ & $31.28 \pm 0.55$ \\
$F_{8}$ & $22.05 \pm 1.21$ & $76.55 \pm 1.57$ & $26.19 \pm 0.12$ \\
$F_{9}$ & $19.15 \pm 0.47$ & $81.09 \pm 0.32$ & $21.41 \pm 2.23$ \\
$F_{10}$ & $13.55 \pm 1.26$ & $92.33 \pm 1.36$ & $16.14 \pm 1.13$ \\
\hline
\end{tabular}

All results expressed as mean $\pm \mathrm{SD}, \mathrm{n}=3$

Table 6: Dissolution profile of flubiprofen ODT with co-processed superdisintegrants

\begin{tabular}{|c|c|c|c|c|c|c|c|}
\hline Time(min) & $\mathbf{F}_{0}$ & $\mathrm{~F}_{1}$ & $\mathbf{F}_{2}$ & $\mathbf{F}_{3}$ & $\mathbf{F}_{4}$ & $F_{5}$ & $F_{6}$ \\
\hline 0 & 0 & 0 & 0 & 0 & 0 & 0 & 0 \\
\hline 05 & $9.05 \pm 1.22$ & $15.3 \pm 1.32$ & $23.13 \pm 1.69$ & $26.38 \pm 1.72$ & $34.05 \pm 2.50$ & $25.07 \pm 1.97$ & $15.95 \pm 2.61$ \\
\hline 10 & $14.15 \pm 1.45$ & $35.3 \pm 2.62$ & $44.06 \pm 1.27$ & $48.75 \pm 2.61$ & $59.95 \pm 4.89$ & $42.05 \pm 1.26$ & $29.64 \pm 0.14$ \\
\hline 15 & $19.95 \pm 2.13$ & $52.65 \pm 1.67$ & $59.35 \pm 2.74$ & $65 \pm 3.11$ & $82.08 \pm 1.31$ & $61.85 \pm 2.33$ & $43.91 \pm 3.88$ \\
\hline 20 & $25.42 \pm 2.09$ & $69.95 \pm 3.40$ & $73.15 \pm 2.13$ & $81.75 \pm 1.66$ & $97.55 \pm 3.40$ & $78.35 \pm 2.92$ & $49.15 \pm 1.84$ \\
\hline 25 & $29.51 \pm 0.83$ & $73.15 \pm 2.74$ & $82.30 \pm 2.18$ & $89.29 \pm 2.55$ & $99.26 \pm 1.84$ & $83.13 \pm 2.62$ & $57.25 \pm 1.02$ \\
\hline 30 & $33.75 \pm 0.57$ & $85.35 \pm 1.26$ & $91.65 \pm 2.50$ & $95.05 \pm 0.36$ & $99.91 \pm 1.22$ & $91.35 \pm 1.43$ & $63.55 \pm 1.09$ \\
\hline
\end{tabular}

After compression, all of the manufactured tablets were assessed for thickness, hardness, weight variation, friability, wetting-time, water absorption ratio, disintegration time, drug content, in vitro drug release and kinetic model studies. All formulations had a hardness range of 3.02 to $3.19 \mathrm{~kg} / \mathrm{cm}^{2}$, indicating acceptable mechanical strength, and friability was well within the range of less than 1.0 per cent. All of the formulations weights were observed to be consistent. The uniformity of drug content was tested for all preparations and confirmed to be consistent. The wetting time of flubiprofen tablets was found to be between 12 and $32 \mathrm{sec}$ while utilize $M$. paradisiaca 
and co-processed superdisintegrants (crospovidone and SSG). The tablets made co-processed superdisintegrants $\left(\mathrm{F}_{4}, 3: 1 \mathrm{ratio}\right)$ had the shortest wetting time of $12 \mathrm{sec}$, water absorption ratios were higher, disintegration time was $15 \mathrm{sec}$, in vitro dispersion time was found 11 sec (Table 5).

The in vitro drug release of pure drug flubiprofen control formulation $\left(\mathrm{F}_{0}\right)$ was found $33.75 \pm 0.57 \%$, formulation with different ratios of co-processed superdisintegants (crospovidone and SSG, 1:1, 1:2, $1: 3,3: 1,2: 1$ ratio, $F_{1}-F_{5}$ ), the drug was found $85.35 \pm 1.26,91.65 \pm$ $2.50,95.05 \pm 0.36,99.91 \pm 1.22,91.35 \pm 1.43 \%$, respectively. Formulation $\left(\mathrm{F}_{6}\right)$ prepared with the physical mixture of crospovidone and SSG, drug release was found $63.55 \pm 1.09$. (Table 6).

Formulations $\left(\mathrm{F}_{7}-\mathrm{F}_{10}\right)$ containing unripe banana powder with different concentrations used as superdisintegrant release the drug was found $71.55 \pm 1.09,79.05 \pm 1.21,85.45 \pm 1.20,92.21 \pm 2.68 \%$, respectively in $60 \mathrm{~min}$ (Table 7). When compared to natural superdisintegrant, $M$. paradisiaca, flubiprofen, which comprises coprocessed superdisintegrants (crospovidone and SSG, 3:1 ratio), has improved drug release characteristics, with more than $95 \%$ in $20 \mathrm{~min}$ due to high swelling power and wicking property.

Table 7: Dissolution profile of flubiprofen ODT with unripe banana powder

\begin{tabular}{|c|c|c|c|c|}
\hline $\begin{array}{c}\text { Time } \\
(\mathbf{m i n})\end{array}$ & $\mathbf{F}_{\mathbf{7}}$ & $\mathbf{F}_{\mathbf{8}}$ & $\mathbf{F}_{\mathbf{9}}$ & $\mathbf{F}_{\mathbf{1 0}}$ \\
\hline 0 & 0 & 0 & 0 & 0 \\
\hline 05 & $10.95 \pm 2.61$ & $14.6 \pm 1.22$ & $17.05 \pm 2.05$ & $19.30 \pm 0.56$ \\
10 & $23.64 \pm 0.14$ & $27.6 \pm 1.13$ & $31.95 \pm 4.87$ & $33.30 \pm 4.10$ \\
15 & $37.91 \pm 3.88$ & $41.9 \pm 2.40$ & $44.32 \pm 1.13$ & $49.05 \pm 3.74$ \\
20 & $48.15 \pm 1.84$ & $54.95 \pm 2.12$ & $61.55 \pm 3.04$ & $79.05 \pm 2.19$ \\
25 & $59.25 \pm 1.02$ & $67.55 \pm 2.56$ & $72.55 \pm 1.48$ & $84.25 \pm 1.20$ \\
30 & $71.55 \pm 1.09$ & $79.05 \pm 1.21$ & $85.45 \pm 1.20$ & $92.21 \pm 2.68$ \\
\hline
\end{tabular}

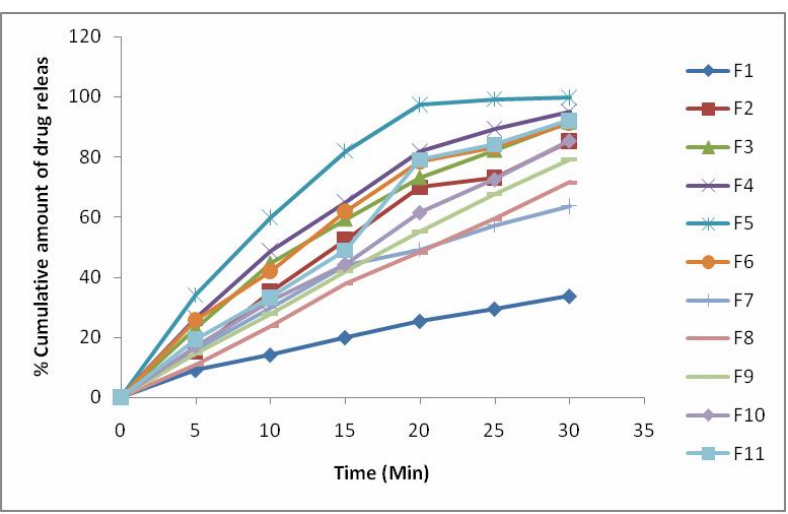

Figure 5: Dissolution studies of flubiprofen orodispersible tablets.

The in vitro drug release data for flubiprofen orodispersible tablets were kinetically analysed utilising the zero order, first order, higuchhi, peppas, hixon crowell model. Flubiprofen formulations followed first order kinetics when plotted; however, drug release might be influenced by disintegration time. The least squares method of statistical analysis of the data provides correlation coefficient values ranging from 0.9534 to 0.9988 .

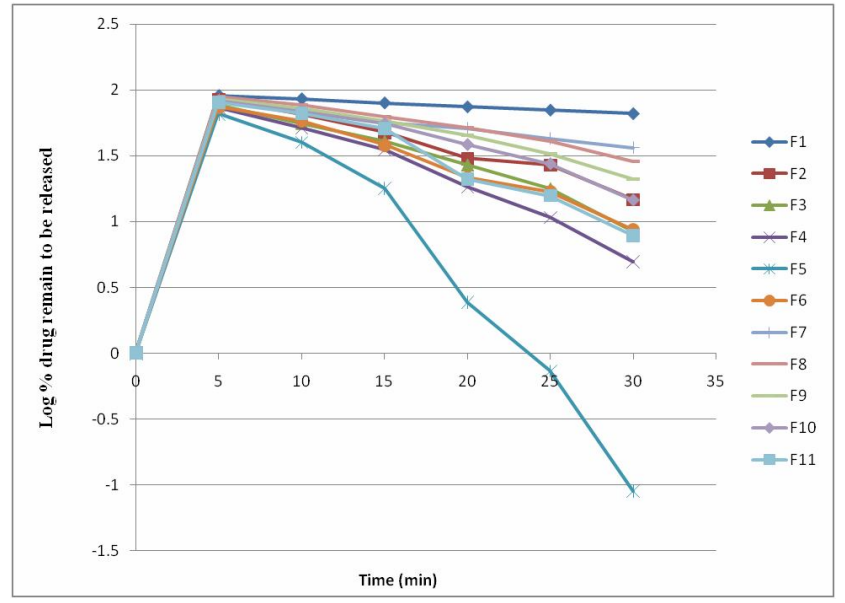

Figure 6: First order kinetics of flubiprofen orodispersible tablets.

\section{Discussion}

Flubiprofen orodispersible tablets were developed by using natural and co-processed superdisintegrants. M. paradisiaca (banana) powder was prepared and extracted with peeled and edible parts of the sliced bananas (Asha Latha et al., 2015).

In unripe banana powder samples, the presence of carbohydrates, saponins, phenols, proteins, gums, mucilage, tannins, lipids, flavonoids, and steroids was determined. UBP has a high carbohydrate content, with starch accounting for 60 to $80 \%$ of the dry weight. On a molar basis, arabinoxylan is a gel-forming polysaccharide that includes around $23 \%$ arabinose and $75 \%$ xylose. Starch, saponins, phenols, proteins, tannins, lipids, flavonoids, and reducing sugars are all found in UBP (Hamsanandini et al., 2015).

Under hot stage microscopy, there was no physical difference between room temperature and $99^{\circ} \mathrm{C}$. Solvent extrusion and bubbling were seen at $100^{\circ} \mathrm{C}$, which is the temperature at which water boils. This showed that the sample included moisture. Between 100 and $190^{\circ} \mathrm{C}$, the powder's physical properties remained constant. A colour change from pale yellow to light brown was seen at $200^{\circ} \mathrm{C}$.

The drug and excipient mixture are compatible, according to FTIR analysis. Because it was determined that the absorption peaks were similar. This signifies that both medications were compatible with certain excipients based on physical observation and FTIR studies (Harshal et al., 2014).

All of the developed formulations exhibited good flow characteristics, compatibility, and compressibility indexes that were within the range of precompression evaluation parameters such as bulk density, tapped density, angle of repose, hausners ration, and compressibility index.

The thickness, hardness, weight variations, friability, wetting-time, water absorption ratio, disintegration time, drug content, in vitro drug release, short-term stability, and kinetic model studies were all evaluated after compression (Patel et al., 2015).

The hardness of all formulations ranged from 3.02 to $3.19 \mathrm{~kg} / \mathrm{cm}^{2}$, showing adequate mechanical strength, while friability was well below 1.0 per cent. The weights of all of the formulations were determined to be consistent. All formulations were examined for uniformity of drug content, which was found to be consistent. 
When using UBP and co-processed superdisintegrants, the wetting time of flubiprofen tablets was found to be between 12 and $32 \mathrm{sec}$. Wetting time was $12 \mathrm{sec}$ for tablets manufactured with co-processed superdisintegrants $\left(\mathrm{F}_{4}, 3: 1\right.$ ratio), water absorption ratios were greater, disintegration time was $15 \mathrm{sec}$ and in vitro dispersion time was 11 sec (Praveen Kumar et al., 2014).

Flubiprofen, which formulated with co-processed superdisintegrants ( $\mathrm{F}_{4}$ crospovidone and SSG in a 3:1 ratio) and has a higher swelling power and wicking property than natural superdisintegrant UBP, has better drug release characteristics, with more than 95 per cent in 20 min (Sathali et al., 2016).

When plotted, the kinetics of flubiprofen formulations followed first order kinetics; however, drug release might be altered by disintegration time. Correlation coefficient results range from 0.9534 to 0.9988 when the data is analysed using the least squares approach.

\section{Conclusion}

From the present, it can be concluded that synthetic superdisintegrants like crospovidone and SSG (co-processed) showed better disintegration property and dissolution profile than the natural superdisintegrant unripe banana powder in the formulation of flubiprofen orodispersible tablets. This is an innovative work that should be recommended for improving rate of disintegration, dissolution, and bioavailability. This method is simple and costeffective.

\section{Acknowledgements}

The authors are thankful to Professor Hemant Kothari (Dean, PG Studies), PAHER University, Udaipur and Dr. V.H. Sastry, Principal, MESCO College of Pharmacy, Hyderabad, for their constant support and encouragement throughout the study.

\section{Conflict of interest}

The authors declare no conflicts of interest relevant to this article.

\section{References}

Asha Latha, M.A.; Shanmukhi, P.; Bhargavi, Ch. and Venkata, S. (2015). Formulation and evaluation of fast dissolving tablets of telmisartan using natural superdisintegrants. Int. J. Innov. Drug. Disc., 5(1): 25-29.

Bandigari, V.; Thadkala, K.; Devara, R. and Aukunuru, J. (2015). Preparation and evaluation of orodispersable tablets of carbamazepine using different superdisintegrating agents. Int. J. Pharm. Tech. Res., 7(3):438-447

Begum, A.; Nagendrakumar, D.; Sharma, N. and Shris and SB. (2015) Formulation and evaluation of fast dissolving tablets of lopermide $\mathrm{HCl}$ using various superdisintegrating agents. Int. J. Univ. Pharm. Bio. Sci., 4(6):2319-8141.

Das, K.; Abdoolah, T.A. and Sounder, J. ( 2020). Formulation and evaluation of stevia oral hygiene preparation: A noble herbal toothpaste. Ann. Phytomed., 9(1):91-97.

Das, K. (2019). Authentic identification and new drug discovery from natural plant based constituents through DNA bar-coding: A challenging task to the researchers. Ann. Phytomed.,8(2):19-27.

Das, K.; Khan, M.S.; Namratha, N.; Swetha, R. and Gezici, S. (2019). Comparative phytochemical screening, elemental content and chromatographic evaluation for detection and quantification of polyphenolic compounds for strong antioxidant activity of various extracts of Abutilon indicum (Link) sweet leaves. Ann. Phytomed., 8(1):36-44.

Das, K. and Gezici, S. (2018). Plant secondary metabolites, their separation, identification and role in human disease prevention. Ann. Phytomed., 7(2):13-24.

Das, K. (2013). Wound healing potential of aqueous crude extract of stevia rebaudiana in mice revista brasileira de farmacognosia. Ann. Phytomed., 23(2):351-357.

Devi, M.; Sharma, A.; Navdeep,; Saroea, S.; Kohli, M. and Bhatt, A.K. (2018). In vitro study of antimicrobial activity of Tinospora cordifolia (Thunb.) Miers plant extracts against selected clinical isolates. Ann. Phytomed., 7(2):76-80.

Doke, O.; Patil, M.K.; Tamboli, D.; Mali, A. and Hake, G. (2015). Development and evaluation of fast dissolving tablets of diltiazem hydrochloride. Int. J. Res. Ayur. Pharm., 6(4):493-501.

Hamsanandini, J. (2015). Formulation and evaluation of orodispersible liquisolid compacts of meloxicam using banana powder as a natural superdisintegrants. Asian J. of Res. in Bio. Pharm Sci., 3(1):25-38.

Harshal, P.; Chhaya, V.; Pravin, J. and Kavita, M. (2014). Development and evaluation of orodispersible tablets using a natural polysaccharide isolated from cassia tora seeds. Inte. Med. Res., 3:91-98.

Hirlekar, R.; Dhadhi, A. and Mehta, K. (2016). Evaluation of effect of various superdisintegrants on disintegration time of orally disintegrating tablets. World J. Pharm. Res., 5(8):846-851.

Malla, V.C.; Mani Kumari, M.; Mariyadas, U.; Sushma, M. and Mounika, N. (2016). Formulation and evaluation of ibuprofen tablets by using different superdisintegrating agents. World J. Pharm. Pharm. Sci., 5(5):875883.

Jyothi Rani, L. (2014). Formulation and in vitro and in vivo evaluation of oral dispersible films of lornoxicam. The Experiment, 24(1):16491655.

Patel, M.; Patel, V.; Surti, N. and Patel, K. (2015). Formulation and evaluation of lorazepam fast dissolving tablets using synthetic and natural disintegrants. Res. J. Recent Sci., 4:185-191.

Prasad, K. and More, S. (2016). Formulation and evaluation of fast dissolving tablets of ciprofloxacin. Int. J. of Adv. in Pharm., 5(3):01-09.

Praveen Kumar, N.; Parvez, N. and Sharma, P.K. (2014). Formulation and evaluation of piroxicam fast dissolving tablets using different natural superdisintegrants. J. of Drug. Del. and Therape., 4(4):55-59.

Priyanka, P. A.; Hasumati, A. R. and Vineet, C.J. (2015). Development and validation of analytical method for simultaneous estimation of lamotrigine and clozapine in synthetic mixture by absorbance correction method. Pharmacy Infopedia Pharmat., 2(6):41-48.

Raja, S. R. P.; Chandrasekhar, R. and Mallikarjun, V. (2015). Formulation and evaluation of fast disintegrating tablets of flupirtine. Int. J. Pharm. and Tec., 7(1):8289-8301.

Rajni, B.; Reecha, M. and Sandeep, A. (2016). Isolation and evaluation of Hibiscus rosa-sinensis leaf mucilage as superdisintegrant. Euro. J. Pharm. Medical Res., 3(8):434-440.

Reddy, A.S.; Rao, M.S.; Ashok, K.A. and Naresh, N.S. (2016). Preparation and evaluation of simvastatin ethosomes. Indo. Am. J. Pharm. Sci., 3(2): $175-186$. 
Revathi, S.; Moulali, SK. and Dhanaraju, MD. (2015). Formulation and evaluation of orodispersible valsartan tablets. Der. Pharm. Let., $7(1): 315-324$.

Sai Padmini, B.; Syamala, S.; Vinod, K.N.; Vijaya Kuamr, V. and Madhusudhan, C. (2014). Formulaion and evaluation of orodispersible tablets of clonazepam using natural superdisintegrants. IOSR J. Pharmcy and Bio. Sci., 9(4):47-52.

Saleh, A.E.R. and Gamal, A.S. (2017). Propafenone $\mathrm{HCl}$ fast dissolving tablet containing subliming agent prepared by direct compression method. Sau. Pharm. J., 25:1086-1092.

Santosh, K.K.; Putta, R.K.; Ravi Shankar, K. and Reddy, G.N.V.C. (2015). Formulation and evaluation of benazepril $\mathrm{HCl}$ immediate release tablets. Euro.J. Biomedical Pharm. Sci., 2(3):452-472.

Sathali, A.A.H. and Suganya, M. (2016). Effect of different natural and synthetic superdisintegrants used in developement of amiodarone hydrochloride fast dissolving tablets: A comparative study. Journal of Cur. Chem. and Pharm. Sci., 6(2):27-38.

Satyanarayana, K.; Sahoo, C.K.; Bhargavi, G. and Sahoo, N.K. (2015). Formulation and optimisation of olanzapine sustained release matrix tablets for the treatment of schizophrenia. Der. Pharm. Let., 7(4):266-73.

Saudagar, R.B. (2015). Formulation characterization and evaluation of mouth dissolving tablet of lisinopril by using dehydrated banana powder as a natural polymer. World J. of Pharm. Res., 4(12):763774

Shravani, B. and Raghavendra, R.N.G. (2015). Formulation and evaluation of fast dissolving tablets of montelukast sodium using co-processed superdisintegrants. Int. J. Drug. Dev.and Res., 6(1):125-134.
Sofia, M. and Jeeja, A.J. (2015). Formulation and evaluation of metformin $\mathrm{HCl}$ mouth dissolving tablet using sublimating agent. Int. J. of pharma. Sci. and Res., 6(7):1050-1055.

Soni, A. and Raju, L. (2015). Formulation and evaluation of fast disintegrating tablet containing hydrochlorothizide. Ind. J. Pharm. Pharm., 2(2): 119-126.

Thakur, K.; Navdeep.; Jaswal, S. and Bhatt, A.K. (2018). Evaluation of antimicrobial potential of root extract of Asparagus racemosus Willd. and bark extract of Juglans regia L. against pathogenic bacterial isolates, Ann. Phytomed., 7(2):64-69.

Uppala, L. and Palle, P. (2015). Development and evaluation of fast disintegrating tablets of ondansetron with natural and synthetic super disintegrating agents. SOJ Pharm. Pharm. Sci., 2(3):1-7.

Vidyadhara, S.; Sasidhar, R.V.L.; Lakshmi, H.D.; Vijetha, P. and Vijetha, K. (2017) Studies on jackfruit seed starch as a novel natural superdisintegrant for the design and evaluation of irbesartan fast dissolving tablets. Int. Med. Res., 6(3):280-291.

Vijaya Sri, K.; Srinivas, D.; Ajay Kumar, Ch. and Ravishanker, D. (2012). Effect of natural polymer on conventional and sustained release properties of indomethacin tablets. Ann. Phytomed., 1(1):20-28.

Vikky, J. Gupta, G.D. and Sandhya, J. (2014). Formulation and evaluation of dispersible tablets of amoxicillin trihydrate using natural disintegrants. Indo Amer. J. of Pharm. Res., 4(06):2910-2918.

Vivek, D.; Renu, B.Y.; Richa, A. and Sachdev, Y. (2017). Formulation design and optimization of novel fast dissolving tablet of chlorpheniramine maleate by using lyophilization techniques. Bul. of Fac. of Pharm., 55:31-39.

V. Rajesh Babu, Suresh Kumar Dev and Khaja Pasha (2021). A comparative study on Musa paradisiaca L. and co- 